\title{
The Egyptian Exploration of the Red Sea
}

\author{
By Dr. Cyril Crossland, Biological Station, Ghardaqa, Red Sea District
}

\begin{abstract}
A
SIX weeks' cruise in the northern Red Sea was undertaken by the University of Egypt and the Fisheries Research Department with the R.E.R.S. Mabahith last winter, as a preliminary to a much more extended exploration planned for the present winter, but this has been postponed owing to the political and financial situations. The main items of our programme were :
\end{abstract}

(1) The structure of the Red Sea Rift.

(2) Hydrography.

(3) The bottom fauna.

Sagh Mahmud el Meligi, of the coastguards service, was in command of the ship. Lines of soundings transverse to the axis of the sea were recorded by Lieut. A. M. Badr of the Royal Yachts, and also off the slopes of certain reefs and islands. The geology of islands was undertaken by Nasri Mitri Shukri under the superintendence of G. Andrew of the University of Egypt. Chemistry was undertaken by Abd el Fattah Mohamed, assisted by Ibrahim Eff. Abu Samra of the Fisheries Research Laboratory and others, who were continuously busy on board ship and whose results are still being worked out. In biology, I was assisted by Dr. Mohamed Kamel el Sabi of the Fisheries, who took charge of the biology on those cruises on which I was unable to be present, with the assistance of H. A. F. Gohar, my assistant in the Biological Station, and Abd el Halim Nasr of the University. Abd el Hafiz Eff. Radwan, instru. ment maker of the University, was indefatigable in keeping the sounding machine in order, a quite essential help.

The Rift Valley structure of the Red Sea needs special methods of investigation. In the first place, the Mabahith is fitted with a Hughes echo sounder, which records the depth beneath the ship every two seconds, drawing a curve representing the form of the bottom as the ship passes above it. In this sea this curve is scarcely ever flat, even the plains which do occur generally showing undulations two to three hundred feet high. The two main features brought out by the sections run transversely to the longer axis of the sea are: (1) the steps by which the bottom descends to its greatest depth, such as would be expected on the sides of a faulted valley and which were postulated as foundations for the Barrier reefs by me in $1907^{1}$; (2) the occurrence of steep submarine hills, some of which reach the surface, such as the well-known Brothers Islets and Daedalus reefs on which lighthouses have been placed. As there is no trace of vulcanism in this part of the Red Sea, these hills must be block mountains resulting from the rifting, as the Brothers and such islands as Zeberged certainly are. These features are illustrated in Figs. 1 and 2, in which the vertical scale is about five times the horizontal, but it is to be borne in mind that echo sounding reduces the slope, and that abrupt summits of scarps, if they occur, are rounded off.
It was hoped that samples of the original rocks of the valley might be obtained, as was done by the John Murray Expedition off the faulted south coast of Arabia, but the whole bottom is buried in a yellow mud. Bottom samples are still under examina. tion, but riddling gives quantities of pteropod shells, etc., or, in shallower water, broken lamellibranchs. Consolidation of this material, especially where it is coarser, near the tops of slopes, is frequent, resulting in either loose friable masses or hard rock. Consolida. tion was found even in the deep area near the Arabian reefs in lat. $25^{\circ} 20^{\prime}$, for which we propose the name "Mabahith Deep", at 1,200 fm. and similar depths.

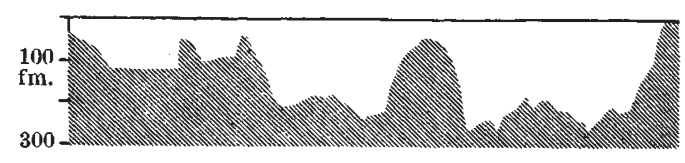

EIG. 1. Section from a point off Ghardaqa, long. $27^{\circ} 18^{\prime} \mathrm{N}$., lat. $33^{\circ} 51 \cdot 9^{\prime} \mathrm{E}$., to the south end of Shadwan Island, showing submarine hills, which, in shallower water, would bear coral reefs. The larger eastern hill bore dead pieces of the reef coral Montipora, the encrusting foraminiferan Gypsina and Lithothamnionea. The latter was found as deep as $52 \mathrm{fm}$. below which only sand and calcrete were found. The vertical scale is about five times the horizontal.

The irregularity of the bottom, and in shallow water its rocky nature, made dredging and trawling difficult, and frequently resulted only in torn nets, even in the case of the triangular dredge with its specially strong net. Some successful hauls were made, but much of our collecting was done by the

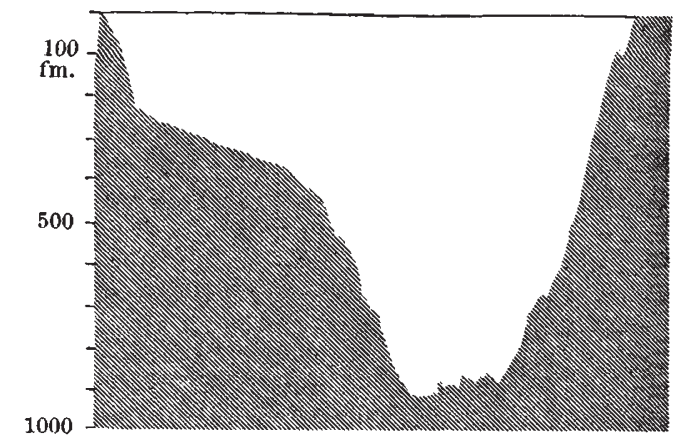

Fig. 2. Section across the deep trough in the Gulf of Aqaba irregularities E., showing a fault shelf on the west and large is about five times the horizontal.

grab, which was successful in depths so great as $600 \mathrm{fm}$. We find that the fauna in deep water con. sists of few species sparsely occurring, and that no area, even in the Mabahith Deep, is free from life. It will be of great interest to discover the origin of this fauna, since, in the present age, the deep fauna of the Indian Ocean is cut off by the shallow sill at the straits of Bab el Mandab, and the temperature of the bottom waters of the Red Sea, $20^{\circ} \mathrm{C}$., is so 
much higher than that of similar depths in the oceans. The numerous large quantities of mud obtained by the grab were almost, but not quite, devoid of life.

The coral cappings on those of the submarine hills which reach the surface or nearly so would seem to be similarly situated ecologically to the atolls of the Indian and Pacific oceans, and, as coral growth round their rims is in full vigour, it was expected, in accordance with the theories of growth of atolls, that their slopes would be covered by fallen coral debris. This was found to be the case only to a quite inconsiderable extent; indeed throughout our exploration, recognisable coral debris is confined to quite shallow water. It was also surprising to find that several shoals examined by the grab are not, as would be expected in a sea so full of coral growth, growing towards the surface, but, though small living corals are present, are evidently in process of decay, as shown by the dead and decayed masses of coral brought up: boring organisms are much more abundant in these masses than in the surface reefs. The decay appears to be rapid, since our soundings are deeper than those recorded only sixty years ago. This state of things corresponds with surface reefs in this neighbourhood, some of which are in full vigour, others stationary or in decay ; some shoals visible from above are covered completely with growing corals, on others are few or none. Our knowledge of coral ecology is still very imperfect. Between the reefs down to $50 \mathrm{fm}$. at least, the bottom is in many places rough and rocky, the nature of the rock being at present unknown. Dead and partly living corals only were secured.

The southern part of the Gulf of Aqaba was also explored. The difference between this and the Gulf of Suez is well known; against the average depths of 30-40 fm. of the flat-bottomed Gulf of Suez we have in Aqaba soundings up to $700 \mathrm{fm}$., but by making courses transverse to the Gulf we discovered a deep trough $900-1,000 \mathrm{fm}$. deep, well over to the eastern side. This narrow gulf, only about 14 miles wide, thus has a depth nearly as great as that of the Red Sea, which itself is deeper in proportion to breadth than any other. From this depth of water the mountains rise sheer, making one of the most wild and desolate coasts in the world, beside which the deserts and mountains of the Gulf of Suez are a mild and smiling landscape. The maritime plain, so characteristic of the Red Sea shores, where it is generally up to 20 miles wide, is here almost absent, but represented even on some of the most abrupt mountain shores by patches of sedimentary rocks clinging to their bases just above water-level. The immense quantities of alluvial gravels which must have resulted from the denudation of the hills in the past disappeared before the Miocene sedimentary rocks were laid down, showing that the rifting of the valley was in two stages, separated by considerable geological time.

${ }^{1}$ Crossland, C., J. Linn. Soc., 31, 26 and 284.

\section{Methods of Estimating Underground Oil Reserves}

$\mathrm{M}^{\mathrm{R}}$ R. V. BILIBIN'S report on his method of estimating underground oil reserves has been accepted by the Organisation Committee of the International Geological Congress, and will be considered at the seventeenth session of that Congress to be held in Moscow in 1937. In the meantime, it is being circulated by the Committee with the view of obtaining criticisms and further contributions to this somewhat complicated problem of accurate assess. ment of oil reserves.

According to Mr. Bilibin's method, the first step is to divide up a general geographical map of the country to be surveyed into various groups of areas by means of colours, the division being based on corresponding available data and geological reasoning. It is suggested that the total surface area be divided into groups of areas as follows: those which have already been exploited for oil; those which, tested by deep drilling, are known to be economically oil-bearing; those considered potentially economically oil-bearing as a result of geophysical and prospecting work; those for general geological reasons considered favourable but which have not been tested, or have been insufficiently tested; those for which no estimate of reserves is available; and those considered as non-oil-bearing.

The total surface area of each of the first four groups is used as a basis of calculation. Distinction is then made between the different types of reserves available in each group. Five categories of reserves are suggested, namely, prepared reserves obtainable from producing wells; explored reserves obtainable from new wells in a prospected horizon and within its fixed boundaries; possible reserves obtainable either from parts of prospected horizons, the boundaries of which have not been fixed, or from discovered, but insufficiently tested horizons; supposed reserves obtainable from the first two groups of areas from horizons proved to be oil-bearing by geological data, or estimated to be so by geological considerations; and possible reserves obtainable from areas where prospecting has been favourable. Reserves falling within the different categories are then estimated either by a method of relation curves based on initial production, well-spacing and number of wells per horizon, or by a saturation method which is a mathe. matical calculation of the ultimate product obtainable from a given horizon, dependent on the volume of the bed, porosity, saturation and recovery factors.

It will be noted that in this method of estimating underground reserves of economic importance, only those are included which are obtainable by wells from each horizon by modern methods of exploitation. Those obtained by so-called secondary methods are not included as it is not at present possible to find out definitely to which horizons these methods can be effectively applied; nor are there sufficient data to show how exploitation can be increased by using these methods. 